\title{
Bilateral Intercostal Lung Herniations: A Rare Incidental Finding in a Dyspneic Patient
}

\author{
Jillian Cooper, MD \\ Thomas Jefferson University, jillian.cooper@jefferson.edu \\ Christine Kurian, MD \\ Thomas Jefferson Univeristy, christine.kurian@jefferson.edu
}

Follow this and additional works at: https://jdc.jefferson.edu/tmf

\section{Part of the Internal Medicine Commons \\ Let us know how access to this document benefits you}

\section{Recommended Citation}

Cooper, MD, Jillian and Kurian, MD, Christine (2020) "Bilateral Intercostal Lung Herniations: A Rare Incidental Finding in a Dyspneic Patient," The Medicine Forum: Vol. 21 , Article 2.

DOI: https://doi.org/10.29046/TMF.021.1.004

Available at: https://jdc.jefferson.edu/tmf/vol21/iss1/2

This Article is brought to you for free and open access by the Jefferson Digital Commons. The Jefferson Digital Commons is a service of Thomas Jefferson University's Center for Teaching and Learning (CTL). The Commons is a showcase for Jefferson books and journals, peer-reviewed scholarly publications, unique historical collections from the University archives, and teaching tools. The Jefferson Digital Commons allows researchers and interested readers anywhere in the world to learn about and keep up to date with Jefferson scholarship. This article has been accepted for inclusion in The Medicine Forum by an authorized administrator of the Jefferson Digital Commons. For more information, please contact: JeffersonDigitalCommons@jefferson.edu. 


\title{
Bilateral Intercostal Lung Herniations: A Rare Incidental Finding in a Dyspneic Patient
}

\author{
Jillian Cooper, MD and Christine Kurian, MD
}

\section{CASE PRESENTATION}

A 63-year-old man with a past medical history of chronic obstructive pulmonary disease (COPD), stage IV sarcoidosis on 3-4 liters of home oxygen and chronic prednisone, moderate aortic stenosis, and a prior aspergilloma for which he had a left upper lobe lung resection presented to the hospital with two weeks of worsening shortness of breath. His symptoms were thought to be multifactorial secondary to community-acquired pneumonia. sarcoidosis flare, and pulmonary edema. He was treated with an increased dose of steroids, antibiotics, and diuretics with symptomatic improvement. He was discharged on $40 \mathrm{mg}$ prednisone daily with a plan to taper as an outpatient.

Notably, CT scan on admission showed under-aerated lung parenchyma via chest wall defects, consistent with bilateral intercostal lung herniations [Figure 1]. He had known longstanding right-sided lung herniation, and in 2010, it was documented that he had recent development of left-sided herniation as well. These were attributed to frequent coughing spells related to his sarcoidosis. He was evaluated by thoracic surgery, and due to his overall poor lung function, surgical intervention was thought to be of little potential benefit. Additionally, given his history of aspergillus, surgical repair was thought to be a higher risk procedure than usual, as repair often involves placement of a foreign body (mesh). Lastly, he did not have much discomfort from the hernias, and thus it was thought that there was a greater risk from intervention rather than benefit.

\section{DISCUSSION}

A lung hernia is an out-pouching of pulmonary parenchyma through a defect in the chest wall. Lung herniations can be classified based on etiology and anatomical location (thoracic and cervical). Intercostal herniations are classified as congenital (18\%), acquiredtraumatic (52\%), or acquired-spontaneous $(30 \%))^{1,2}$ These can develop due to increased intrathoracic pressure with concurrent weaknesses in the chest wall. ${ }^{3}$ Symptoms include pain with inhalation, coughing, or sneezing; shortness of breath; soreness; or swelling. Long-term complications of lung hernias include recurrent pulmonary infections and strangulation. ${ }^{2}$ Few cases of bilateral thoracic lung herniations are documented in the literature. ${ }^{4}$ Repair is often indicated in cases with pain and entrapped lung.
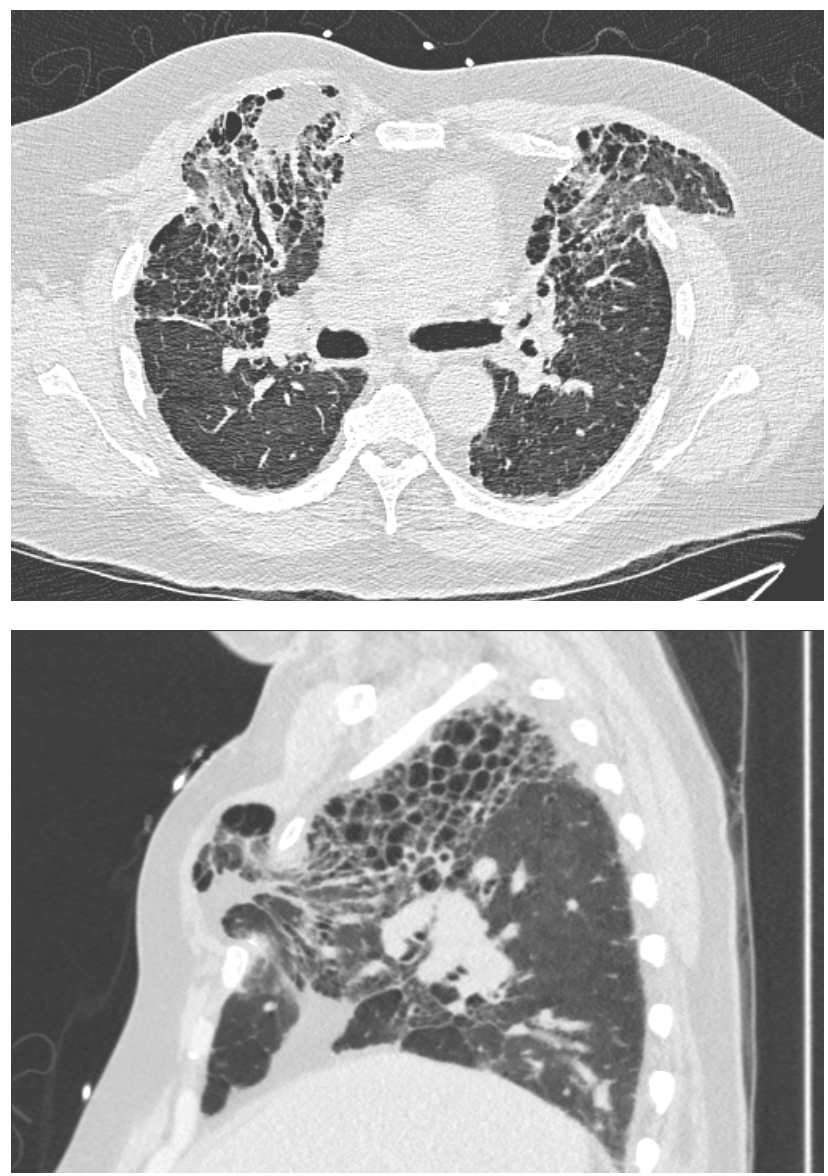

Figure 1: Chronic lung changes of end-stage sarcoidosis with right mid-lung abnormality corresponding to under-aerated right middle lobe lung parenchyma via chest wall defect, also seen on left, secondary to chronic intercostal herniation of lung.

\section{REFERENCES}

1. Hiscoe, D.B., \& Digman, G.J. (1955). Types and incidence of lung hernias. The Journal of thoracic surgery, 30(3), 335-42.

2. Tapsoba, T.W., Grapin-Dagorno, C., Bonnard, A., \& El-Ghoneimi, A. (2019). Isolated congenital inter-costal pulmonary hernia: a case report. Journal of medical case reports, 13(1), 232

3. Davakis, S., Syllaios, A., Mpaili, E., Sdralis, E., \& Charalabopoulos, A. (2020) Minimally invasive oesophagectomy and emerging complications: intercostal lung hernia. Annals of the Royal College of Surgeons of England. 102(3), e73-e74

4. Rahman, M., Buchan, K.G., Mandana, K.M., \& Butchart, E.G. (2006). Bilateral cervical lung hernia with $\mathrm{T} 1$ nerve compression. The Annals of thoracic surgery, 81(2), 716-8. 